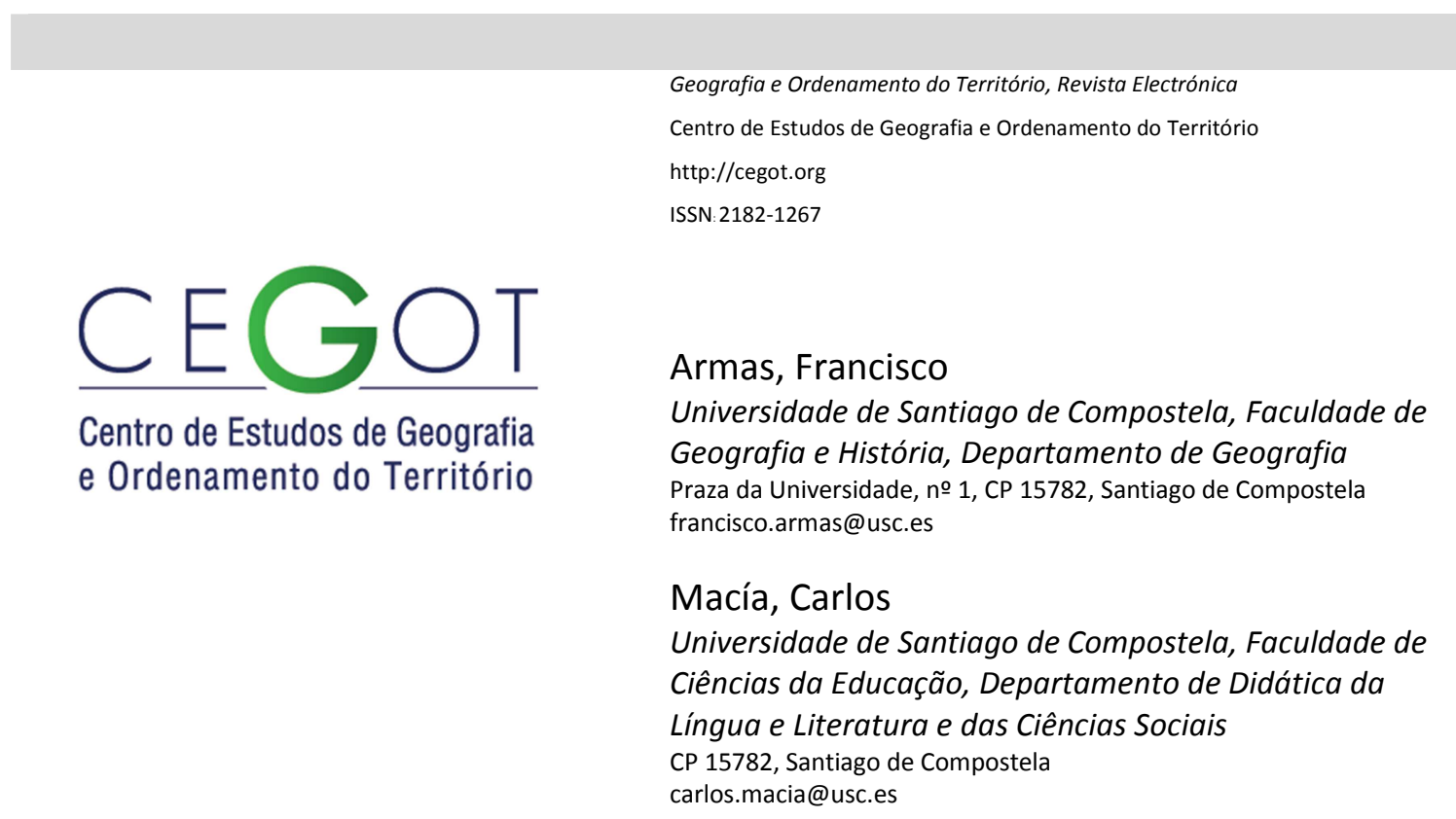

\title{
Desenvolvimento rural e sociedade da informação em Portugal. Análise do fosso digital de segunda geração na região Norte
}

Referência: Armas, Francisco; Macía, Carlos (2015). Desenvolvimento rural e sociedade da informação em Portugal. Análise do fosso digital de segunda geração na região Norte. (GOT), n.o 7 (junho). Centro de Estudos de Geografia e Ordenamento do Território, p. 65-83, dx.doi.org/10.17127/got/2015.7.003

\section{Resumo}

A difusão das tecnologias da informação e da comunicação estiveram muito presentes nas políticas regionais da União Europeia nas duas últimas décadas. Inicialmente, o objetivo centrava-se em "conectar" a população à Internet e estabelecer redes de telecomunicações que permitissem a acesso à Internet através de banda larga. Hoje em dia, e a grande escala, este objetivo foi alcançado em grande parte da União Europeia, contudo a difusão da Sociedade da Informação vai além dos simples "utilizadores de Internet". No presente artigo estuda-se a dimensão de um novo fosso digital no Norte de Portugal, que separa os utilizadores básicos da Internet dos que consomem serviços avançados. A utilização destes serviços avançados seria fulcral para estimular as áreas rurais.

Palavras-chave: Sociedade da Informação, Novas Tecnologias, Fosso Digital, Desenvolvimento Rural, Norte de Portugal.

\section{Abstract}

The spread of the Information and Communication Technologies have been very present in the regional policies of the European Union in the last two decades. In the beginning, the aim was centered in "connect" the citizen to the Net and establish telecommunication networks for access to Internet through broadband. Nowadays, in broad terms, this aim was reached for the most European Union, but the spread of the Information Society goes 
beyond to be "Internet users". In this article the dimension of a new digital divide in Northern Portugal was studied. This new digital divide separates the basics Net users of those that consume advanced services. The use of these advanced services are what could boost development process in rural areas.

Keywords: Information Society, New Technologies, Digital Divide, Rural Development, Northern Portugal.

\section{Introdução}

A revolução tecnológica que deu origem à Sociedade da Informação e ao processo de globalização no qual estamos inseridos, configurou um novo modelo de sociedade. Nesta nova sociedade emergente, o trabalho físico tem vindo a ser substituído pelo trabalho cognitivo e do ponto de vista económico, o trabalho nas fábricas foi em grande parte substituído pelo trabalho nos serviços (Fukuyama, 2000). Por outro lado, as tecnologias da informação e da comunicação, e em particular a Internet, permitem a transmissão de informação e a comunicação entre qualquer parte do planeta a um custo muito baixo, o que levou a alguns autores a introduzir conceitos como "a morte da distância" ou o "fim da Geografia" (Cairncross, 2001).

Perante esta revolução tecnológica e o auge da nova Sociedade emergente, a União Europeia mostrou, já desde finais do século $X X$, um enorme interesse em expandir a implantação da Sociedade da Informação e em difundir as novas tecnologias (Comissão Europeia, 2000). Era o momento de desenhar políticas para criar uma rede de telecomunicações que tornassem possível o acesso à Internet através da banda larga, dotar de equipamento tecnológico os lares, e incentivar os cidadãos a fazerem parte do ciberespaço. Não se tratava de uma tarefa simples, e prova disso é que hoje em dia, apesar dos avanços obtidos, ainda existem territórios e setores sociais que estão à margem da Sociedade da Informação. Tratava-se de conectar a Europa e os seus estados membros, retirar o máximo proveito das mudanças que estavam a ocorrer fruto da revolução tecnológica, criar prosperidade, e diminuir a distância entre o mundo rural e urbano, que esteve a crescer desde o início da Revolução Industrial (Sáez et al., 2001). 
Ao analisar a evolução da difusão das tecnologias da informação e da comunicação desde começos do século XXI, o progresso foi notável. Como facilmente se pode verificar, esse avanço não registou a mesma intensidade em todos os países europeus, nem todos alcançaram o mesmo nível de equipamento, utilizadores e serviços de Internet. Mas esta evolução leva-nos a refletir se o fosso digital tradicional, tal como se entendia até agora, foi superado no mundo ocidental. Cada vez são menos os cidadãos que estão à margem desta nova sociedade emergente, grande parte dos lares estão conectados à internet através de alta velocidade, e os utilizadores da Internet multiplicam-se dia após dia, assim como os serviços disponíveis on-line. Também se generalizaram muitos dos dispositivos que uma década antes nem sequer existiam ou pouco se utilizavam devido ao seu elevado custo; é o caso dos Smartphones, dos PDAs, dos Tablets, Netbooks, das Smart TV, dos e-books, etc. Estes dispositivos comportam-se, na prática, como micro computadores tanto pelas suas características como pelas funções que desempenham, e já estão amplamente difundidos na sociedade. Prova disso é que, segundo dados do Eurostat (2013), para o conjunto da União Europeia (UE 28), quase metade dos cidadãos entre 16 e 74 anos utilizam a Internet fora do lar ou do trabalho, através destes dispositivos.

Os avanços alcançados na última década, tanto a nível do equipamento tecnológico nos lares, como do número de utilizadores de Internet e dispositivos conectados, leva-nos a consentir que o fosso digital terá sido superado. O fosso digital "tradicional" separava aqueles grupos sociais e territórios que estavam à margem da Sociedade da Informação. Este facto poderia ocorrer devido a, basicamente, dois fatores: os cidadãos que queriam aceder à Internet mas não tinham as infraestruturas necessárias (banda larga, equipamento), ou porque, apesar de terem acesso à Internet não a utilizavam por não terem a formação necessária, ou por não lhe reconhecerem utilidade. Este facto levou a alguns autores a diferenciar os cidadãos utilizadores da Internet (utilizadores reais) dos que não a utilizavam apesar de terem a possibilidade de o fazer (utilizadores potenciais) (Lois et al. 2010; Armas, 2009; Macía, 2007). É notório que este fosso digital ainda tem presença em determinados setores sociais, como por exemplo os cidadãos idosos ou a população com um baixo nível de estudos e que não consideram úteis estas tecnologias, bem como as regiões mais periféricas com um elevado índice de envelhecimento. 
$\mathrm{Na}$ atualidade, este fosso digital tradicional foi substituído por um novo fosso ao qual se deu o nome de "fosso digital de segunda geração" (Lois et al., 2014; Armas, 2012). Este novo fosso digital está relacionado com os serviços avançados de Internet e separa os utilizadores que fazem um uso básico da Internet - que utilizam os motores de busca para encontrar informação, e se comunicam tanto via e-mail ou através das redes sociais, etc. - ou os que consomem serviços avançados - como o comércio eletrónico, o teletrabalho, a formação online, etc. É este novo fosso o que deve ser enfrentado, uma vez que a isto está associada a plena imersão na Sociedade da Informação.

O simples acesso à Internet para consultar e transmitir informação ou comunicar-se, não é suficiente para estimular os processos de desenvolvimento, e concretamente o desenvolvimento das áreas rurais periféricas numa situação de declínio económico e demográfico. Contudo, pode ser uma oportunidade de desenvolvimento para estas áreas o consumo intensivo de serviços avançados da Internet. Como afirma Drucker (2001), o verdadeiro impacto das tecnologias da informação e da comunicação não será o acesso a uma grande quantidade de informação, mas sim o comércio eletrónico. A Internet será o maior canal de difusão e distribuição mundial de bens e serviços, e neste meio as distâncias parecem desaparecer.

No presente artigo, estuda-se o fenómeno do fosso digital de segunda geração e a difusão dos serviços avançados da Internet na região Norte de Portugal. Da mesma forma, também se faz uma reflexão sobre o papel que podem ter as tecnologias da informação e da comunicação para estimular processos de desenvolvimento em áreas rurais. A Internet é cada vez mais popular, aproximando-se hoje em dia dos três mil milhões de utilizadores. Mas um simples uso da Internet não é suficiente para alcançar uma verdadeira imersão na Sociedade da Informação, pois é necessário que a informação gere conhecimento e que estas tecnologias possam impulsionar processos de desenvolvimento.

\section{O meio rural na Sociedade da Informação}

A origem de boa parte dos problemas presentes no meio rural atual poderia referenciar-se a começos do século XIX, no período em que a Revolução Industrial e o desenvolvimento do 
capitalismo começavam a materializar profundas transformações tecnológicas, económicas, sociais e culturais. Neste contexto, os espaços rurais partiam já de uma situação de desvantagem em relação às áreas urbanas, uma vez que tinham menos possibilidades de negócio. Isso levou a que a população das áreas rurais emigrasse para os principais núcleos urbanos onde iniciavam atividade em setores económicos mais rentáveis. Este facto desencadeou, progressivamente, um forte processo de despovoamento, envelhecimento demográfico e declínio da sua economia. Por outro lado, o facto destes serem espaços periféricos, a distância, e as más redes de comunicações com as principais urbes, foram retraindo e condicionando a sua evolução económica e social.

Mas, na Sociedade da Informação esta situação pode mudar, uma vez que se abrem novas possibilidades de desenvolvimento para estes espaços. O que entendemos por meio rural? Qual é o limite entre o meio rural e o urbano? Foram muitos os autores que tentaram definir e delimitar, com um êxito limitado, o meio rural (Cloke, 1977; Hoggart, 1990; Clout 1993; Cloke and Goodwin, 1993; Halfacree, 1993; Lázaro Araujo, 1995; Ceña Delgado, 1995; García Sanz, 1998; Guibertau Cabanillas, 2002; Waldorf, 2006; Sabalain, 2011; Rodríguez, 2011). A maior parte dos investigadores admite que não existe uma definição de aceitação unânime do que é o meio rural, existindo uma grande diversidade de critérios para delimitálo.

As posturas existentes no momento de delimitar o meio rural revelam grandes diferenças (Rodríguez, 2005), com reflexões que relativizam a vigência da distinção entre o rural e o urbano (Camarero, 1993), aqueles que defendem a rutura entre o rural e o agrário (García Sanz, 1998), e os que consideram inútil ou impossível qualquer tentativa de delimitar concetualmente o termo rural (Sancho Hazak, 1997; Bericat, 1993). As possíveis definições de ruralidade dependem, em grande medida, das unidades de análise e das variáveis escolhidas para estudá-lo, assim como da diversidade de elementos que o formam (Lázaro Araujo, 1995; Márquez Fernández, 2002; Rodríguez, 2005; Waldorf, 2006; Scott y Gelan, 2007; Coburn et al., 2007).

Tradicionalmente o meio rural identificava-se com o agrário, e em outras ocasiões definia-se como oposição ao urbano com um carácter pejorativo. Na atualidade, as definições do meio rural são muito variadas, ainda que se tenda a concebê-lo como um sistema plural que abarca componentes sociológicos, geográficos, funcionais e económicos (Florencio 
Calderón, 2000). Investigações do âmbito académico de diversos países assinalam a necessidade de procurar alternativas no momento de selecionar os critérios que se utilizam para delimitar e definir o meio rural, combinando duas ou mais variáveis, tais como a densidade populacional, o tamanho dos lugares, a distância às grandes cidades, entre outros (Sabalain, 2011). A este respeito, Hewitt (1992) assinala que a maior parte das definições do que é o rural baseiam-se, em linhas gerais, em quatro variáveis: tamanho demográfico, densidade populacional, proximidade às áreas urbanas, e principal atividade económica.

Quando surgiram as primeiras delimitações do meio rural, foram tratadas pela maior parte dos autores, como um conceito unidimensional. Nestas delimitações, quase todos os critérios que se usavam baseavam-se na variável populacional, omitindo aspetos tão importantes como os fatores socioculturais (Bosak e Perlman, 1982). Contudo, outros autores assinalaram a necessidade de especificar melhor os critérios a partir dos quais se definiam as realidades rurais e urbanas. Segundo Rodríguez (2011), existe um amplo consenso em relação a que alguns critérios, como o acesso aos serviços e a dotação tecnológica, não podem ser fatores que discriminem o rural em relação ao urbano, já que as dinâmicas dos espaços rurais se estão alterando, e a diversidade é cada vez maior. Este autor aposta na necessidade de alterar a forma de medir as áreas rurais e a combinação de critérios de modo a poder apreender a heterogeneidade do mundo rural.

Existe uma tendência a generalizar os problemas mais comuns das áreas rurais, assumindo que estes são homogéneos e omitindo que existem situações complexas e variadas, que estão muito longe dessa homogeneidade (McDonagh, 1998). Echeverri (2011) refere que o rural, no imaginário político, se considera como algo marginal e portador de numerosos problemas, contudo isso não corresponde à realidade, dado que o meio rural tem inúmeras potencialidades. Na atual Sociedade da Informação, as áreas rurais têm perante si muitas possibilidades de atenuar o declínio económico e social em que estão imersas uma grande parte delas. A distância às principais urbes, que foi um dos fatores que propiciou o seu declínio, desaparece com a chegada das tecnologias da informação e da comunicação e, especialmente, com a maior expressão da difusão da Internet.

É cada vez está mais generalizado o sentimento de que as áreas rurais constituem um património coletivo, o que torna necessária a sua preservação e integração nas estratégias de crescimento e bem-estar da sociedade em geral. A sociedade atual preocupa-se com o 
risco de deterioração das condições ambientais, em especial dos recursos naturais, da água, dos bosques e das espécies animais e vegetais. A este respeito, a população rural, e em especial a agrária, deve manter a estabilidade ecológica e preservar o ambiente natural (Comissão Europeia, 1996; Comissão Europeia, 2003).

Alguns autores como Hervieu (1995) defendem que a agricultura continua a ser o eixo central do desenvolvimento rural, apesar de existirem outras contribuições para a vida económica e social do campo. Apesar disso, também refere que é necessário mudar a noção do campo como espaço de produção agrária, no contexto da vida que interessa ao conjunto da cidadania. Com outro ponto de vista, Izquierdo (2002) defende que a revitalização das economias rurais passa pela sua diversificação, tanto pela valorização dos recursos endógenos, como pela implementação de atividades económicas exteriores que seja mais vantajoso iniciar no meio rural por razões estratégicas (qualidade ambiental, boas comunicações, banda larga, melhor qualidade de vida, etc.).

Existe uma ampla variedade de opiniões no seio da comunidade científica que estuda os espaços rurais, quanto às estratégias e atividades económicas que se podem estimular para revitalizar o meio rural do futuro. As novas tecnologias e a Sociedade da Informação oferecem uma série de oportunidades, contudo é necessário saber aproveitá-las. A Internet torna possível a anulação virtual das distâncias, mas deve-se ter em conta que a tecnologia, por si só, não gera desenvolvimento, e é necessário capital humano qualificado que saiba retirar dela o melhor rendimento. No presente artigo, estuda-se o fosso digital de segunda geração no Norte de Portugal, isto é, o fosso que separa os cidadãos que fazem um uso básico da Internet, como é o caso da procura de informação ou da comunicação, dos que consomem serviços avançados, como é o caso do comércio eletrónico, a banca on-line, o trabalho à distância, a formação em on-line, etc.

O comércio eletrónico e as distintas formas de trabalho à distância podem viabilizar a revitalização do mundo rural, invertendo a tendência regressiva da dinâmica económica, estimulando os fluxos de emigração de retorno (Blanco Romero e Cánoves Valiente, 1998; Ray e Talbot, 1999; Richardson e Gillespie, 2003; Grimes, 2003; Simpson et al., 2003). O teletrabalho apresenta-se como uma alternativa para integrar a população mais jovem qualificada que regista, na atualidade, as maiores taxas de desemprego. No caso do comércio eletrónico, cada consumidor pode comprar ou vender em qualquer parte do 
mundo através da Internet. Numa sociedade predominantemente terciária, não se pode continuar a manter as mesmas regras que estruturaram a construção da sociedade industrial. É necessário que as empresas levem a cabo uma profunda reestruturação dos seus modelos de gestão comercial, configurando redes que as ligam ao mercado mundial.

O comércio eletrónico converter-se-á numa das possibilidades de negócio e emprego no meio rural da Sociedade da Informação. Atualmente, e em maior medida no futuro, a Internet regista uma grande expansão e a prova disso é que cada dia são mais os internautas que compram e vendem através da Internet. Drucker (2001) afirmou que o comércio eletrónico será, na Sociedade da Informação, o que foi o comboio para a Revolução Industrial. Trata-se duma revolução nova e sem precedentes que provocará mudanças rápidas na economia, e por isso é necessário que as áreas rurais saibam aproveitar esta oportunidade. No comércio da Sociedade da Informação as distâncias são eliminadas, há um só mercado e a concorrência já não tem fronteiras. Cada empresa tornase transnacional (Drucker, 2001), e simultaneamente vai abrindo caminho no mercado.

O trabalho à distância nasce como uma nova forma de organização da atividade laboral no contexto da Sociedade da Informação. A partir deste momento é possível o trabalho desde o domicílio familiar, nas deslocações profissionais a partir de aeroportos, hotéis ou outros espaços de transição (teletrabalho móvel), centros ou escritórios satélite desenhados para reduzir as deslocações de trabalhadores (Martínez, et al., 2006). Através do teletrabalho, as áreas rurais podem receber população que no passado cumpria o seu desempenho laboral no escritório de uma cidade, o que contribuirá para fixar população e reduzir os movimentos migratórios. Autores como Cairncross (2001) assinalam que as novas tecnologias vão diluir a delimitação entre o trabalho e a residência. O lar voltará a ser um lugar de convivência de muitos aspetos da vida humana, deixando de ser um simples espaço de dormitório. Com a difusão do teletrabalho, o lar adquire novas funções, como lugar de trabalho, de formação, etc.

Nestas condições, faz todo o sentido que no meio rural se promova uma verdadeira imersão na Sociedade da Informação difundindo o consumo de serviços avançados da Internet, reduzindo assim o fosso digital de segunda geração. Com o desaparecimento das distâncias na Sociedade da Informação, as regiões periféricas devem saber oferecer os seus produtos e serviços a qualquer cidadão do mundo. O fosso digital tradicional está a ser superado, 
contudo é o momento de dar um passo mais, principalmente nas áreas rurais, que têm perante si uma boa oportunidade para alterar a dinâmica regressiva que sofrem boa parte delas.

\section{A difusão da Sociedade da Informação em Portugal}

Há mais de uma década que a União Europeia (UE) iniciou políticas para difundir a Sociedade da Informação e as Tecnologias da Informação e da Comunicação. Nessa altura, a prioridade era dotar as casas de equipamento tecnológico e levar a Internet a todas as regiões da União, independentemente do quão periféricas eram. Paralelamente, a UE apoiou o financiamento de projetos de alfabetização digital para que cidadãos, empresas e administrações passassem a utilizar a Internet. À medida que se criavam "serviços web", as exigências de banda larga foram maiores, pelo que foi necessário desenhar um novo objetivo: difundir a banda larga por toda a União Europeia para dar cobertura a estes novos serviços que incluíam serviços interativos, disponibilidade de arquivos de áudio e vídeo, voz IP, entre outros.

Do desafio que a Europa tinha nos finais do século XX e começos do século XXI, de difundir o equipamento e uso das tecnologias da informação e da comunicação entre cidadãos, empresas e administrações, surgiu o conceito conhecido como o "fosso digital". Este fosso separava aqueles que utilizavam Internet (básica) dos que não a utilizavam, independentemente do motivo estar relacionado com o facto de não ter os meios necessários ou por não lhe reconhecer nenhum interesse. Mas passadas quase três décadas, a situação que se refere à conetividade alterou-se significativamente. Cada dia são menos aqueles que estão à margem da Sociedade da Informação por não dispor de mecanismos de acesso, seja pelos dispositivos ou pela ausência de conetividade (banda larga). A evolução dos indicadores mais básicos para o conjunto da União Europeia, e concretamente para Portugal, foi notável nos últimos anos, apesar de neste progresso não ter existido um processo de convergência, levando a que existam ainda notórias diferenças entre países.

Para analisar o fosso digital anteriormente descrito, que denominamos por "fosso digital tradicional", utilizam-se três dos indicadores mais básicos para medir a difusão das novas 
tecnologias: os indivíduos que nunca utilizaram um computador, os lares com Internet, e os lares com banda larga. Na União Europeia e segundo os dados da Eurostat (2013), apenas seis países tinham percentagens superiores a $30 \%$ de cidadãos que nunca usaram um computador, mas em dezasseis deles mais de $80 \%$ dos cidadãos já o tinham feito alguma vez ou o faziam-no habitualmente. Se analisarmos a situação de Portugal nos últimos anos, a evolução deste indicador foi muito importante; se no ano 2006 metade da população portuguesa nunca tinha usado um computador, no ano 2013 mais do 70\% já o tinha usado. Nessa altura, os problemas de conetividade eram um importante obstáculo a superar, sobretudo nas regiões mais periféricas, dado que o investimento requerido por parte das empresas privadas para oferecer este serviço, não seria rentabilizado dada a escassa densidade de população, além de que se tratavam de coletivos na sua grande maioria idosos, e com um índice de utilizadores de Internet muito baixo.

Se a difusão do uso do computador foi importante nos últimos anos, será muito mais o uso da Internet e a extensão da banda larga em casa. No ano 2006, em treze países da União Europeia (UE-25) mais de metade da sua população nunca tinha usado Internet, enquanto no ano 2013 , em vinte países (UE-28) mais do $70 \%$ da população era já utilizadora da Internet. No caso de Portugal, a evolução do número de utilizadores da Internet teve um crescimento notável neste período ao passar de $35 \%$ para $62 \%$ da população (ver figura 1). Contudo, o maior progresso dos três indicadores estudados registou-se na difusão da banda larga nos lares. No ano 2006 a grande maioria de países que formavam a União Europeia (UE-25) tinham menos de $50 \%$ das casas conectadas à Internet através de banda larga; apenas superavam esse limiar a Finlândia, Dinamarca e os Países Baixos. Sete anos mais tarde, em 2013, a situação era consideravelmente distinta, dado que mais da metade dos países tinham $70 \%$ ou mais dos suas casas conectadas à Internet através de banda larga. Se estudarmos o caso concreto de Portugal, o progresso foi surpreendente, uma vez que em sete anos se triplicou o número de casas com banda larga, passando de $22 \%$ no ano de 2006 a 62\% em 2013 (ver figura 1).

Os dados analisados nas linhas precedentes levam-nos a afirmar o importante avanço que ocorreu na Europa em geral e em Portugal em particular, no que ao equipamento e à conetividade se refere. Hoje em dia são muitos os dispositivos que estão ao alcance de boa parte dos cidadãos, assim como o acesso à Internet. Atualmente já não é necessário dispor 
de um computador para realizar boa parte das tarefas mais habituais; os smartphones, os tablets, etc. são como micro computadores conectados à Internet que permitem a navegação on-line, a consulta do correio eletrónico, o uso das redes sociais, transações financeiras, consumo de serviços, ou o desempenho da sua função de navegadores ao dispor de sistemas de posicionamento global (GPS). A tecnologia evolui a um ritmo muito rápido bem como o número de serviços disponíveis via web e daí a importância de ir além do uso básico desta tecnologia.

Figura 1: Evolução da difusão da Sociedade da Informação em Portugal

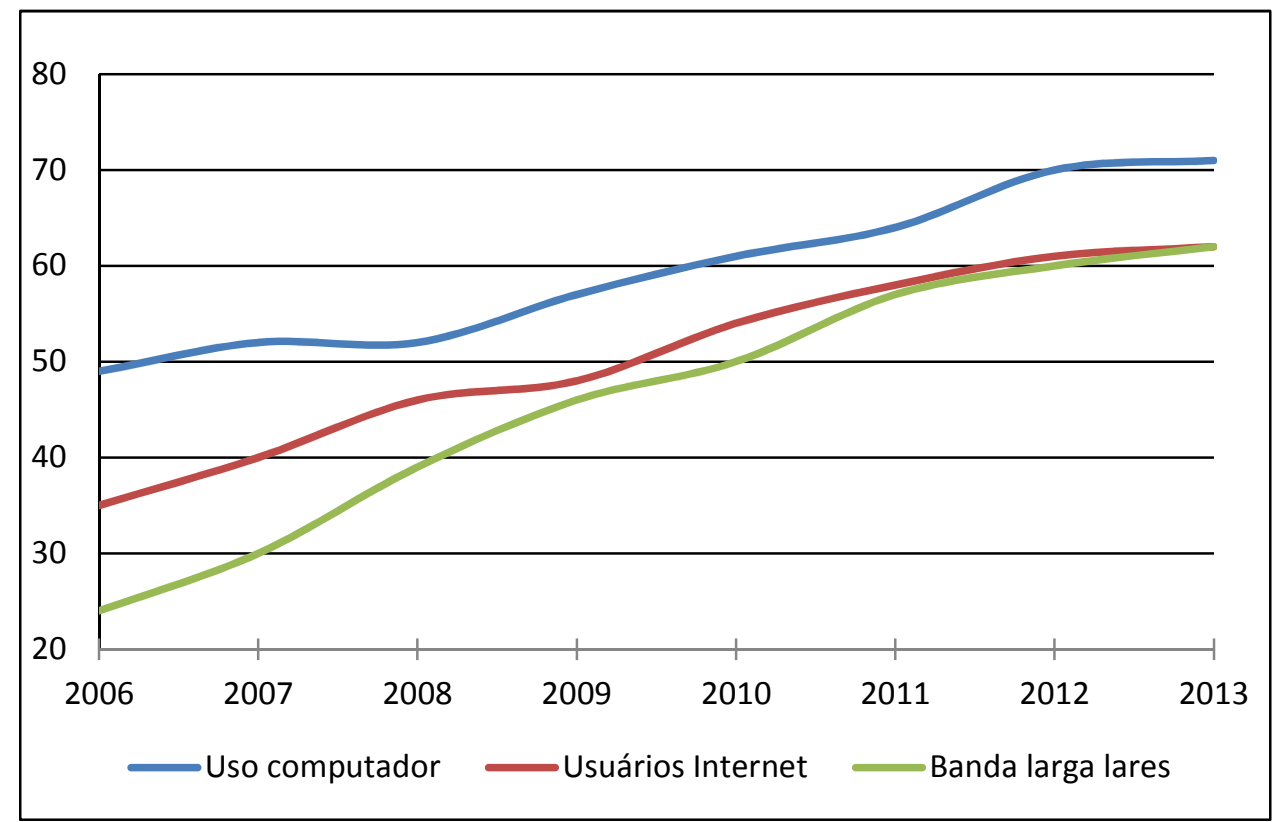

Figura 1: Evolução da difusão da Sociedade da Informação em Portugal Fonte: Eurostat (vários anos)

Este progresso leva a refletir sobre a relevância do fosso digital na atualidade. Do nosso ponto de vista, o fosso digital tradicional foi superado, pelo menos no mundo ocidental. 0 fosso que separa os territórios e os setores sociais que estão à margem da Sociedade da Informação é, hoje em dia, cada vez mais estreito, mas está a ser substituído por um novo fosso digital conhecido como o "fosso digital de segunda geração" (Lois et al., 2014). Este fosso está relacionado com os serviços avançados de Internet e é o que separa os utilizadores que acedem à Internet quase exclusivamente para consultar informação e para comunicação, seja qual for o meio, dos que a utilizam de um modo mais amplo, consumindo serviços avançados como o comércio eletrónico, a banca on-line, a formação on-line, o trabalho à distância, a administração eletrónica, etc. Este novo fosso é o que se deve 
enfrentar para alcançar uma plena inserção na Sociedade da Informação. Nos países onde a difusão das tecnologias da informação e da comunicação é maior, o fosso digital tradicional ou o fosso no acesso, reduz-se à mínima expressão, estando limitado às pessoas idosas ou às que têm uma formação mais básica e que não compreendem a verdadeira potencialidade destas tecnologias.

\section{Análise do fosso digital de segunda geração na Região Norte}

Os dados analisados até ao momento indicam-nos que no contexto europeu e concretamente em Portugal, o fosso digital tradicional, isto é, o fosso no acesso, está a ser superado. Contudo, os avanços relacionados com a conetividade e equipamentos não demonstram uma plena difusão da Sociedade da Informação, sendo simplesmente uma fase conquistada. Na atualidade, boa parte dos cidadãos que são utilizadores da Internet, são maioritariamente utilizadores básicos. Estes usos limitam-se à consulta de informação, à comunicação através do correio eletrónico, ao uso das redes sociais, e a um número de serviços muito limitados.

Se analisamos os dados do Eurostat a nível europeu, observa-se que para o conjunto da União Europeia (UE-28) no ano 2013, o 75\% dos utilizadores de Internet eram capazes de utilizar motores de busca para encontrar informação, uma das tarefas mais simples da Internet. Contudo, tendo em conta um serviço avançado como é a administração eletrónica, apenas dois em cada dez europeus realizava esta tarefa on-line. No caso de Portugal $65 \%$ dos internautas, utilizavam a Internet para procurar informação, mas unicamente $23 \%$ o faziam para usar a banca on-line.

Estes dados evidenciam que, na atualidade, é preciso estimular políticas para enfrentar um novo fosso digital, o "fosso digital de segunda geração" (Lois et al., 2014) e que está relacionada com o consumo de serviços avançados de Internet. Este novo fosso digital separa os utilizadores que acedem à Internet quase exclusivamente para consultar informação e comunicação, daquelas que o fazem de uma forma mais ampla, utilizando o comércio eletrónico, a administração eletrónica, a banca on-line, a formação on-line, o trabalho à distância, etc. Nas regiões onde o avanço da Sociedade da Informação é mais 
intenso, o fosso digital tradicional é menor, estando confinado unicamente às pessoas idosas ou aquelas com uma formação muito básica, enquanto o fosso digital nos serviços avançados tem ainda uma notável expressão.

Para estudar o consumo dos serviços avançados de Internet na região Norte de Portugal, teve-se em conta a difusão de cinco deles: o comércio eletrónico, a banca on-line, a administração eletrónica, as chamadas por Internet (voz IP), e a formação on-line. Os indicadores destes serviços foram cruzados com outros três indicadores sociodemográficos com o objetivo de explicar a desigual difusão espacial. Selecionaram-se a formação dos cidadãos, o envelhecimento demográfico, e o tamanho dos lugares.

Do ponto de vista metodológico é preciso ressaltar que não existem dados sobre os diferentes usos de Internet por parte dos cidadãos disponíveis a um nível de desagregação superior ao regional, concretamente à divisão NUTS II (Nomenclatura das Unidades Territoriais Estatísticas da União Europeia). No caso de Portugal, as NUTS II correspondemse às cinco grandes regiões continentais, Norte, Centro, Lisboa, Alentejo e Algarve, além das Regiões Autónomas dos Açores e da Madeira. Os dados usados na presente investigação são do Instituto Nacional de Estatística de Portugal, do "Inquérito à Utilização de Tecnologias da Informação e da Comunicação pelas Famílias" (2012), e foram tratados com SPSS. Este inquérito, com periodicidade anual, tem como finalidade a observação do avanço da Sociedade da Informação na cidadania, empresas, na administração pública, etc. a nível regional (NUTS II).

A análise do consumo de serviços avançados de Internet em Portugal revelou que existem importantes diferenças a nível regional. Nos cinco indicadores estudados, em quatro deles a região de Lisboa é a que melhores resultados regista, enquanto que a região Norte tem todos os seus valores abaixo da média nacional. A maior desigualdade foi encontrada na administração eletrónica, concretamente no envio de formulários preenchidos on-line às administrações públicas. Neste indicador as diferenças entre a região com os valores mais altos, que é Lisboa, e a que regista os mais baixos, a Região Autónoma dos Açores, há quase dezoito pontos percentuais. Esta situação assemelha-se à da região Norte, muito distante e também a quase dezassete pontos percentuais (ver figura 2). 


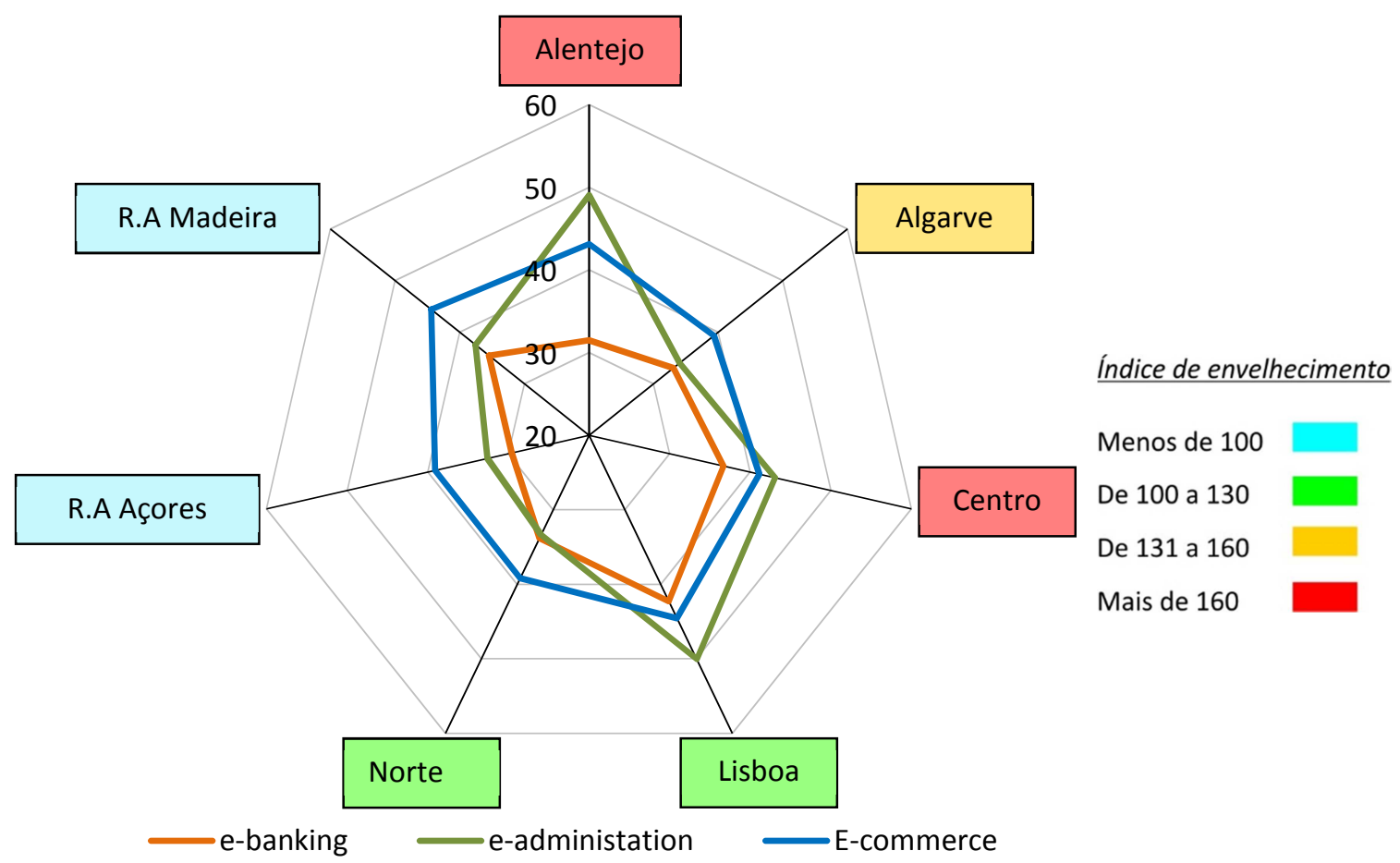

Figura 2: O consumo de serviços avançados de Internet em Portugal Fonte: Eurostat (vários anos)

Um dos motivos pelo qual a região de Lisboa se destaca em todos os indicadores estudados é talvez, o facto de ter uma proporção de população com estudos superiores muito superior às outras seis regiões. Nesta região mais de $20 \%$ dos seus cidadãos tem estudos superiores, quase $7 \%$ acima da média nacional e mais de $10 \%$ acima da região do Alentejo, a que tem menos população com estudos superiores, com pouco mais de $11 \%$. Outro aspeto a destacar quanto a Lisboa, é que o índice de envelhecimento não é muito acentuado, já que nesta região se registam 125 pessoas com 65 anos ou mais por cada 100 menores de 15 anos, situação muito distinta da das regiões do Alentejo e Centro onde há mais de 170 pessoas de 65 anos ou mais, por cada 100 menores de 15. Este elevado grau de envelhecimento supõe um importante obstáculo à superação do défice de inserção na Sociedade da Informação e, sobretudo, ao consumo de serviços avançados de Internet.

Um dos aspetos que deve ser salientado, apesar de ser necessário analisar estes dados com certa cautela por não estar presente nas mesmas fontes, é que a região de Lisboa tem valores superiores, em quatro dos cinco indicadores analisados, à média da União Europeia (UE-28). Se temos em conta os valores da média nacional, também é importante sublinhar 
que tanto no comércio eletrónico, como na banca on-line e na administração eletrónica, se registam valores superiores à média europeia.

Ao analisar a situação da região Norte comprovou-se a existência do fosso digital de segunda geração dado que, dos cinco indicadores que se estudaram todos estão abaixo da média. Inclusive em três deles, comércio eletrónico, administração eletrónica e na realização de chamadas via voz IP, está na penúltima posição das sete regiões do país. Não ocorre o mesmo se tivermos em conta os indicadores que fazem referência aos usos mais básicos da Internet, onde a região Norte está acima da média em quase todos eles. É o caso do uso de motores de busca para encontrar informação, ler notícias on-line ou consultar wikis. Este facto revela que estamos perante um novo fosso digital de segunda geração, um fosso digital que separa os cidadãos que fazem um uso básico de Internet dos que consomem serviços avançados. E este é um aspeto fundamental para alcançar uma verdadeira inserção na Sociedade da Informação.

Outro aspeto estudado foi o consumo dos serviços avançados de Internet em função do tamanho dos lugares. O Instituto Nacional de Estatística de Portugal diferencia três tipologias de lugares: as áreas densamente povoadas, as áreas medianamente povoadas, e as áreas pouco povoadas. Ao cruzar os dados dos serviços avançados com o tamanho dos lugares obtiveram-se dados significativos. Nas regiões do Norte, Agarve, Centro e as Regiões Autónomas dos Açores e da Madeira, detetaram-se valores de utilização de serviços avançados superiores à média nacional no caso das áreas pouco povoadas. É o caso da região Norte e Algarve relativamente à realização de cursos on-line; Algarve, Centro, Alentejo e Açores em relação à utilização da banca on-line; Centro e Alentejo na administração eletrónica, e também Centro e Alentejo para o caso do comércio eletrónico.

Este facto comprova as possibilidades que têm as tecnologias da informação e da comunicação para as áreas periféricas, sobretudo no momento de estimular processos de desenvolvimento através de certos serviços, tais como comércio eletrónico ou o trabalho à distância. Em Portugal começa-se a observar a penetração destes serviços nas áreas rurais e esta é a direção a seguir; o objetivo é difundir o consumo de serviços avançados de Internet e superar o novo fosso digital, o fosso digital de segunda geração. 


\section{Conclusões}

A difusão das tecnologias da informação e da comunicação desde começos do século XXI foi muito importante na Europa e também em Portugal. Nessa altura, o objetivo era dotar os lares de equipamento tecnológico necessário, conectá-los à Internet e promover a sua utilização por parte dos cidadão. Esta tarefa era muito mais complicada de levar a cabo nas áreas rurais periféricas, tanto do ponto de vista técnico como económico. Difundir equipamentos que permitissem o acesso à Internet através de banda larga era custoso e pouco rentável. Nestes espaços a densidade populacional é muito baixa e com elevados índices de envelhecimento, daí que rentabilidade económica era pequena.

Neste contexto, surgiu o conceito do fosso digital, que separava territórios e cidadãos que estavam "conectados" à Internet dos que estavam à margem desta revolução tecnológica. Hoje em dia, a conetividade ao ciberespaço não está associada aos lares, já que se converteu numa conetividade permanente. Os dispositivos móveis que se generalizaram e se estenderam por toda a sociedade nos últimos anos, pelo facto de terem um custo relativamente baixo, tornaram possível a conetividade permanente. O número de utilizadores de Internet cresceu de forma muito notória nos últimos anos, bem como a difusão da banda larga, o que fez com que o conceito de fosso digital, tal como se entendia até agora, fosse superado, pelo menos nos países desenvolvidos.

Esta progressão no número de utilizadores de Internet não implica que se realize em pleno o potencial da Sociedade da Informação. Um simples uso da Internet, como pode ser a consulta de informação, a comunicação, o uso do correio eletrónico ou a utilização das redes sociais, não gera conhecimento nem impulsiona processos de desenvolvimento. Para isto será necessário um consumo de serviços avançados de Internet, tanto por parte da população como por parte das empresas e das administrações públicas. Entre estes serviços destacam-se o comércio eletrónico, o trabalho à distância, a formação on-line, a administração eletrónica, a banca on-line, etc. Estamos, portanto, perante um novo fosso digital, entre os utilizadores de Internet que consomem este tipo de serviços e os que não o fazem; trata-se de um fosso digital de segunda geração. 
As tecnologias da informação e da comunicação podem estimular processos de desenvolvimento em áreas rurais periféricas, mas deve-se saber aproveitar as oportunidades que estas tecnologias oferecem. O comércio eletrónico e o trabalho à distância podem ser duas das oportunidades mais importantes na Sociedade da Informação para alterar a dinâmica económica e demográfica de boa parte do meio rural. No caso do Norte de Portugal, constatou-se que se superou, em maior ou menor grau, do fosso digital tradicional, contudo ainda falta percorrer um longo caminho para superar o fosso que existe nos serviços avançados da Internet. Por outro lado, também se revelou que certas áreas rurais de Portugal, depois de analisar os dados do Inquérito à Utilização de Tecnologias da Informação e da Comunicação pelas Famílias segundo o grau de urbanização, publicada pelo Instituto Nacional de Estatística de Portugal, estão a caminhar numa boa direção, já que têm, em alguns indicadores, valores acima da média nacional. Este facto tem que ser considerado, ao mesmo tempo, com alguma cautela devido a que o nível máximo de

desagregação dos dados utilizados foi o regional (NUTS II). É provável, portanto, que o estudo do fenómeno a um maior nível de detalhe, revele muitas heterogeneidades.

\section{Referências bibliográficas}

ARMAS QUINTÁ, Francisco José (2009). Sociedade da información e desenvolvemento rural: Análise de novos procesos sociais e territoriais en rexións periféricas, o caso de Galicia. Tesis Doctoral. Santiago de Compostela: Universidade de Santiago de Compostela, Servizo de Publicacións e Intercambio Científico.

ARMAS QUINTÁ, Francisco José (2012) “Website Production in Galicia and its visibility on the Net. Moving Towards the Knowledge Society" In: AGALI Journal: Journal of Social Sciences and Humanities, № 2, pp. 77-92.

BERICAT ALASTUEY, E. (1993). "La teoría del vacío rural”. En: El desarrollo rural a las puertas del siglo XXI. Sevilla: Junta de Andalucía, pp. 41-54.

BLANCO ROMERO, Asunción; CÁNOVES VALIENTE, Gemma (1998). "El teletrabajo, ¿Alternativa para el mundo rural?". En: Actas IX Coloquio de Geografía Rural. Vitoria, Universidad del País Vasco, AGE, p. 52-62.

BOSAK, Jeanine; PERLMAN, Baron (1982). "A review of the Definition of Rural” In: Journal of Rural Community Psychology. Vol. 3 and № 1, pp. 3-34.

CAIRNCROSS, Frances (2001). The death of distance 2.0. How the communications revolution will change our lives. London: Texere, $317 \mathrm{p}$.

CAMARERO, L. (1993). Del éxodo rural y del éxodo urbano. Madrid: Ministerio de Agricultura, Pesca y Alimentación

CEÑA DELGADO, Felisa (1995). "Planteamientos económicos del desarrollo rural: una perspectiva histórica". En: RAMOS, Eduardo; CRUZ, Josefina (coords.). Hacia un nuevo sistema rural. Madrid: Ministerio de Agricultura, Pesca y Alimentación, pp. 91-129. 
CLOKE, Paul (1977). “An index of rurality for England and Wales”. Regional Studies. Ashford: 1977, vol. 11. p. 31-46.

CLOKE, P. and GOODWIN, M. (1993). “Rural change: structured coherence or unstructured incoherence?”. In: Terra. 105(3), 166-174.

CLOUT, H. (1993) "What is the rural?". En: CLOUT, H. European experience of rural development. London: Rural Development Commission.

COBURN, Andrew F. et al. (2007). "Choosing Rural Definitions: Implications for Health Policy". Rural Policy Research Institute. Columbia (US): University of Missouri-Columbia.

COMISIÓN EUROPEA (1996). “La declaración de Cork: Por un paisaje rural vivo”. Conferencia Europea de Desarrollo Rural [en línea]. Comisión Europea. Cork, 7 al 9 de noviembre de 1996, [ref. de 22-03-2006]. Disponible en Internet:

http://redrural.mapya.es/web/temas/conclusiones_jornadas/Documentos/Cork_es.pdf

COMISIÓN EUROPEA (2000). eEurope: Una sociedad de la información para todos [en línea]. Lisboa: Comisión Europea, [ref. de 23-10-2006]. Disponible en Internet:

http://europa.eu.int/ISPO/docs/policy/docs/e_europe/COM(99)_es.pdf.

COMISIÓN EUROPEA. (2003). "Declaración de Salzburgo. Plantar la simiente para el futuro rural: Por una política de altura a nuestras ambiciones". Segunda Conferencia Europea sobre el Desarrollo Rural [en línea]. Salzburgo (Austria), 12 al 14 de noviembre de 2003, [ref. de 04-04-2006]. Disponible el Internet:

http://ec.europa.eu/agriculture/ecrd2003/index_en.htm.

DRUCKER, Peter (2001). “Detrás de la revolución de la información”. La Factoría [en línea]. Outubro-xaneiro de 2001, no 13 [ref. de 04-07-2006]. Dispoñible na Internet:

http://www.lafactoriaweb.com/articulos/drucke13.htm.

ECHEVERRI PERICO, Rafael (2011). "Reflexiones sobre lo rural: economía rural, economía de territorios". En DIRVEN, Martine et al. (2011). Hacia una nueva definición de "rural" con fines estadísticos en América Latina. Santiago de Chile: Comisión Económica para América Latina y el Caribe (CEPAL), Naciones Unidas, pp. 13-20.

FLORENCIO CALDERÓN, Alfredo (2000). "El desarrollo local y el desarrollo rural: el papel de los pequeños municipios". En: PÉREZ RAMÍREZ, Bartolomé ; CARRILLO BENITO, Emilio (coords.). Desarrollo local: manual de uso. Madrid: ESIC, p. 527-554.

FUKUYAMA, Francis (2000). La gran ruptura. Barcelona: Ediciones B. 405 p.

GARCÍA SANZ, B. (1998). La sociedad rural ante el siglo XXI. Madrid: Ministerio de Agricultura, Pesca y Alimentación.

GRIMES, Seamus (2003). "The digital economy challenge facing peripheral rural areas". In: Progress in Human Geography. № 27, vol. 2, p. 174-193.

GUIBERTAU CABANILLAS, Antonio (2002). "Fortalezas y debilidades del modelo de desarrollo rural por los agentes locales". En: MÁRQUEZ FERNÁNDEZ, Dominga (dir.); CHAMPETIER, Yves. Nuevos horizontes en el desarrollo rural. Madrid: Akal.

HALFACREE, K.H (1993). "Locality and social representation: space, discourse and alternative definitions of the rural”, Journal of Rural Studies, 9(1), 23-27.

HERVIEU, Bertrand (1995). "El espacio rural europeo entre la ruptura y el desarrollo". En: RAMOS, Eduardo; CRUZ, Josefina (coords.). Hacia un nuevo sistema rural. Madrid: Ministerio de Agricultura, Pesca y Alimentación. P. 27-48.

HEWITT M. (1992). "Defining rural areas. Impact on health care policy and research". In: GESLER W. and RICKETTS TC (eds.). Health in Rural North America. New Brunswick, NJ: Rutgers University Press.

HOGGART, K. (1990). "Let's do away with rural”. In: Journal of Rural Studies. Vol. 6, Num. 3, 245-257.

IZQUIERDO VALLINA, Jaime (2002). Manual para agentes de desarrollo rural. Madrid: Instituto de desarrollo rural, $453 \mathrm{p}$. 
LÁZARO ARAUJO, Laureano (1995). “El desarrollo rural en el contexto de la Unión Europea”. En: RAMOS, Eduardo; CRUZ, Josefina (coords.). Hacia un nuevo sistema rural. Madrid: Ministerio de Agricultura, Pesca y Alimentación, pp. 237-255.

LOIS GONZÁLEZ, Rubén Camilo; ARMAS QUINTA, Francisco José; MACÍA ARCE, José Carlos (2014). "Consumption of advanced internet services in urban areas: a case study of Madrid" In: O'DONOGHUE, Daniel P. (ed.). Urban Transformations: Centres, Peripheries and Systems. United Kingdonm: Ashgate Publishing, pp. 27-38

LOIS GONZÁLEZ, R. C.; MACÍA ARCE, J. C.; ARMAS QUINTÁ, F. J. (2010): “ICT inequalities in the Spanish urban system". In: Journal of Urban and Regional Analysis, vol. 2, no2, pp. 19-32.

MACÍA ARCE, Xosé Carlos (2007). Sociedad de la Información en la Europa Atlántica. Análisis de casos en Galicia e Irlanda (ca.1990-2000). Santiago de Compostela: Universidade de Santiago de Compostela.

MARTínez SÁNCHEZ, A.; PÉREZ PÉREZ, M; DE LUIS CARNICER, P.; VELA JIMÉNEZ, M. (2006): “Trabajo y flexibilidad: efecto moderador sobre los resultados de la empresa" en Cuadernos de Economía y Dirección de la Empresa, vol. 29, pp. 229-262.

MCDONAGH, John (1998). "Rurality and Development in Ireland, the need for debate? In: Irish Geography, Vol 31, № 1, p. 47-54.

MÁRQUEZ FERNÁNDEZ, Dominga (dir.); CHAMPETIER, Yves (2002). Nuevos horizontes en el desarrollo rural. Madrid: Akal, $177 \mathrm{p}$.

RAY, Christopher; TALBOT, Hilary (1999). "The information Society and rural development”. En: CRANG, Mike; CRANG, Phil; MAY, Jon. Virtual Geographies. Bodies, space and relations. London: Routledge, 322 p.

RICHARDSON, Ranald; GILLESPIE, Andrew (2003). "The call of the wild: Call centers and economic development in rural areas". Growth and Change 34 (1), p. 87-108.

RODRÍGUEZ, Adrián (2011). "Pertinencia y consecuencias de modificar los criterios para diferenciar lo urbano de lo rural". En DIRVEN, Martine et al. (2011). Hacia una nueva definición de "rural" con fines estadísticos en América Latina. Santiago de Chile: Comisión Económica para América Latina y el Caribe (CEPAL), Naciones Unidas.

RODRÍGUEZ RODRÍGUEZ, Manuel (2005). Revisión de las políticas de desarrollo rural y su incidencia en los municipios rurales de la provincias de Almería. Los servicios de proximidad como base para su reformulación. Málaga: Analistas Económicos de Andalucía-Fundación Unicaja.

SÁEZ PÉREZ, Luís Antonio; PINILLA NAVARRO, Vicente; AYUDA BOSQUE, María Isabel (2001). "Políticas ante la despoblación en el medio rural". AGER. Revista de estudios sobre despoblación y desarrollo rural, no 1. p. 211233.

SANCHO HAZAK, R. (1997). "Estructura demográfica y tipificación de los asentamientos y áreas rurales españolas". En: Agricultura y sociedad en la España Contemporánea. Madrid: Ministerio de Agricultura, pp. 173-224.

SABALAIN, Cristina (2011). "El concepto de rural en los países de la región". En DIRVEN, Martine et al. Hacia una nueva definición de "rural" con fines estadísticos en América Latina. Santiago de Chile: Comisión Económica para América Latina y el Caribe (CEPAL), Naciones Unidas.

SCOTT, Alister; GILBERT, Alana; GELAN, Ayele (2007). “The Urban-Rural Divide: Myth or Reality?" In: SERG Policy Brief. № 2, Aberdeen, Scotland (UK): The Macaulay Institute.

SIMPSON, Lyn; DAWS, Leonie; PINI, Barbara; WOOD Leanne (2003). "Rural Telework: Case Studies from the Australian Outback". In: New Technology, Work and Employment. Vol. 18, p. 115-126.

WALDORF, Brigitte S. (2006). “A Continuous Multi-Dimensional Measure of Rurality: Moving Beyond Threshold Measures". Long Island, California: Annual Meeting of the American Agricultural Economics Association, July, 24-27, 2006. 